\title{
Finite Component Approach for Modelling Entropy of Motor Road Pavements to Assess Their Efficiency
}

\author{
Mikhail Gennadjevich Goryachev ${ }^{1}$ \\ ${ }^{1}$ The Moscow state automobile and road technical university, Russian Federation \\ Correspondence: Mikhail Gennadjevich Goryachev, The Moscow state automobile and road technical university, \\ 125319, Moscow, Leningradski prospect, 64, Russian Federation.
}

Received: January 9, 2015

Accepted: January 29, 2015

Online Published: July 25, 2015

doi:10.5539/mas.v9n8p140

URL: http://dx.doi.org/10.5539/mas.v9n3p140

\begin{abstract}
In statistical physics, the irreversible processes are characterized by the same value as entropy. Entropy represents a measure of system disorder consisting of many components. Originally ordered systems in irreversible processes lose their order, so that the system entropy increases. Therefore, one can judge by the size of entropy about the degree of order in the system. This article gives a brief description of the new physical and mathematical solution taken as a basis of the model of entropy accumulation and defects development processes within the motor road pavements for the prognosis and evaluation of their operational integrity and durability.
\end{abstract}

Keywords: road pavement, entropy, operational integrity

\section{Introduction}

Road pavement appears to be extremely difficult object for modelling. The model should simulate complex processes occurring in the road pavement under the conditions of automobile traffic and environment changes elastic deformations, plastic displacements, and destruction. The present paper may be regarded to as an attempt to develop a universal physical-mathematical model of the road pavement and the process of its destruction at its operation. To this effect there are proposed new energy criteria based on physical laws of accumulation of potential strain energy of destruction of road pavement layers and soil subgrade from the work of multiply applied external loads (Goryachev, 2014a; Goryachev, 2014b; Smirnov \& Aleksandrov, 2009; Smirnov, 1989). Abroad the entropy approach within the road science and practice is applied for evaluation of coating flatness (Andrei, 2000). Moreover, approaches may be very different (Chakrabarti \& Boltzmann-Gibbs, 2000; Chakrabarti \& Chakrabarty, 2005), but always based on the known principles of thermodynamics (Gaskell, 2003; Sandler, 1989; Martyushev \& Seleznev, 2006).

For simplified demonstration Figure 1 shows a three-layer system "road pavement - subgrade" (sand, gravel, asphalt), each layer of which is represented by a set of large quantity of finite components of spherical shape.

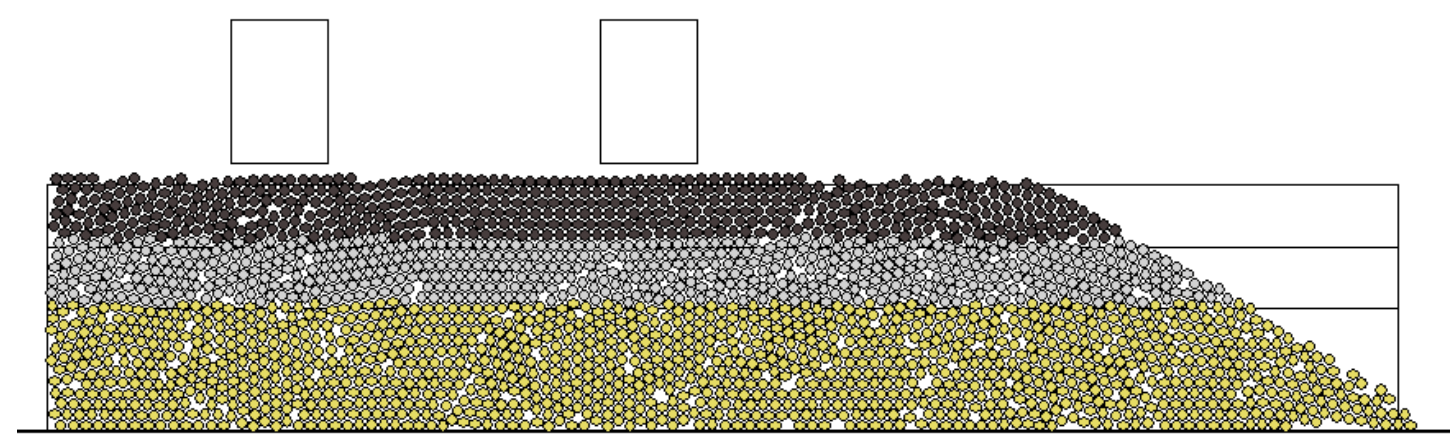

Figure 1. Model of the three-layer system of a two-lane motor road (cross section)

This model is based on the predominating principle of modern mathematics, which consists in replacing the macroscopic objects by objects of smaller sizes (preferably infinitesimal sizes, or at least sizes much smaller than 
the typical size of layers themselves or automobile wheels). In accordance with this principle, the layers of road pavement are demonstrated as a totality of a large number of separate circular components (see Fig. 1). The used method of modelling is similar to the method of smoothed particles or SPH-method (Smoothed Particle Hydrodynamics), which has been recently applied in computer graphics to produce highly realistic images of different environments that are prone to fragmentation. Also modelling method is similar to the method of finite components, differing from it in that the nodes of the grid can be moved in accordance with the laws of classical dynamics, and the grid itself meanwhile changes its configuration.

\section{Methodology}

\subsection{Model Intent}

Introduction of the road pavement within the model is executed in a two-dimensional space X-Y. Provided that the axis $\mathrm{X}$ is located in the horizontal direction across the motor road, and the axis $\mathrm{Y}$ is located in the vertical direction. Elimination of the third dimension allows at a selected number of components to increase the linear dimensions of the system modelled in the directions $\mathrm{X}$ and Y. Otherwise, the program calculations would manifold lengthened. During the calculations, there were used up to 10000 components. Eliminated (invisible) axis $Z$ would be located in the horizontal direction along the motor road pavement. While turning the plane along the $\mathrm{Z}$ direction, it is possible to search for unsafe (reference) cross-sections and perform modelling for the newly created plane X-Y.

Kinematic state of each road pavement component $i$ is defined by four variables: the Cartesian coordinates of its centre $\left(\mathrm{x}_{\mathrm{i}}, \mathrm{y}_{\mathrm{i}}\right)$ and the Cartesian velocity components $\left(\mathrm{v}_{\mathrm{xi}}, \mathrm{v}_{\mathrm{yi}}\right)$.

To calculate the forces acting on the components of the road surface, used is the following method. Certain component $\mathrm{i}$ undergoes force action on the part of each surrounding it component $\mathrm{j}$ :

$$
F_{i}=\sum_{j=1}^{N_{C}}\left(F_{i j}^{E}+F_{i j}^{V}\right), \mathrm{N},
$$

Where $F_{i j}^{E} ; F_{i j}^{V}$ - forces of the elastic and viscous interaction of components i and $\mathrm{j}, \mathrm{N}$;

$\mathrm{N}_{\mathrm{c}}$ - the total number of components within a road pavement model.

To calculate the forces in each pair of components, there should be pre-calculated the distance $\mathrm{r}_{\mathrm{ij}}$ between their centres $\mathrm{S}_{\mathrm{i}}\left(\mathrm{x}_{\mathrm{i}}, \mathrm{y}_{\mathrm{i}}\right)$ and $\mathrm{S}_{\mathrm{j}}\left(\mathrm{x}_{\mathrm{j}}, \mathrm{y}_{\mathrm{j}}\right)$ :

$$
r_{i j}=\sqrt{\left(x_{i}-x_{j}\right)^{2}+\left(y_{i}-y_{j}\right)^{2}}, \mathrm{~m} .
$$

Forces between the components are calculated in the approximation of viscoelastic interaction

$$
\begin{aligned}
& F_{x i j}=\left\{\begin{array}{l}
c\left(d_{c}-r_{i j}\right) \cdot\left(x_{i}-x_{j}\right) / r_{i j}+d \cdot\left(v_{x i}-v_{x j}\right), \text { if } r_{i j}<\alpha \cdot d_{c} ; \\
0, \text { if } r_{i j} \geq \alpha \cdot d_{c} ;
\end{array}\right. \\
& F_{y i j}=\left\{\begin{array}{l}
c\left(d_{c}-r_{i j}\right) \cdot\left(y_{i}-y_{j}\right) / r_{i j}+d \cdot\left(v_{y i}-v_{y j}\right), \text { if } r_{i j}<\alpha \cdot d_{c} ; \\
0, \text { if } r_{i j} \geq \alpha \cdot d_{c},
\end{array}\right.
\end{aligned}
$$

Where $\mathrm{F}_{\mathrm{xij}}$ and $\mathrm{F}_{\mathrm{yij}}-$ Cartesian components of the force $\mathrm{F}_{\mathrm{ij}}, \mathrm{N}$;

$c$ - stiffness coefficient of the elastic interaction of components, $\mathrm{N} / \mathrm{m}$;

$\mathrm{d}$ - viscosity coefficient of interaction (damping), $\mathrm{N} \cdot \mathrm{s} / \mathrm{m}$;

$\alpha$ - factor of interaction restriction.

Viscous friction coefficient $d$ is related to the internal friction within the material, and is determined by the typical distance of sound waves attenuation within the material. The $\alpha$ factor is connected with the material's tensile strength (represents a ultimate tensile strain at rupture or tensile testing).

For modelling the road pavement destruction, in the model there must be followed the evolution of the component system, for which there should be calculated the trajectory of motion of each of the components. The trajectories are found by solving the equations of motion of individual components that can be recorded on the basis of Newton's second law. 


$$
\begin{aligned}
& m_{c} \cdot \frac{d^{2} \cdot x_{i}}{d t^{2}}=\sum_{j=1}^{N_{C}}\left(F_{x i j}^{E}+F_{x i j}^{V}\right)+k_{v} \cdot v_{x i} ; \\
& m_{c} \cdot \frac{d^{2} \cdot y_{i}}{d t^{2}}=\sum_{j=1}^{N_{C}}\left(F_{y i j}^{E}+F_{y i j}^{V}\right)-m_{c} \cdot g+c_{c-s} \cdot r_{m i i}+k_{v} \cdot v_{y i},
\end{aligned}
$$

Where $\mathrm{m}_{\mathrm{c}}$ - mass of a road pavement component, $\mathrm{kg}$;

$\mathrm{t}$ - time, $\mathrm{s}$;

$\mathrm{g}-$ acceleration of gravity, $\mathrm{m} / \mathrm{s}^{2}$;

$\mathrm{c}_{\mathrm{c}-\mathrm{s}}$ and $\mathrm{k}_{\mathrm{v}}$ - coefficients of stiffness and viscosity of viscoelastic interaction of the i-th component with underlying surface;

$\mathrm{r}_{\mathrm{mii}}$ - distance of mutual intrusion of the $\mathrm{i}$-th component of road pavement into the underlying surface, $\mathrm{m}$;

$\mathrm{v}_{\mathrm{xi}}$ and $\mathrm{v}_{\mathrm{yi}}-$ Cartesian components of the velocity vector of the $\mathrm{i}$-th component, $\mathrm{m} / \mathrm{s}$.

Set of equations of the form (4) for all $\mathrm{N}_{\mathrm{c}}$ components describes evolution of road pavement in the course of time.

At the initial point of time, road pavement components are randomly placed by the uniform law in the geometrical field - the cross-section of the road. After the start of integration of motion equations, components, moving, get into local equilibrium positions. Thus, realized is a random dense packing of components. At the same time, the pavement model comes into a stable condition. Later within the model there is simulating the automobile wheel effect on the top layer of road pavement.

With a significant mechanical stress on the road pavement material, it loses its initial cohesion, starts to deforming and destructing, in particular, there appear microdisplacement, cracks, and voids. Within the developed model the effect of the initial cohesion loss is simulated as follows. After preparation of the model of road pavement layers (random close packing), "initial binding" of components is produced in the model. For this a two-dimensional array $\mathrm{K}(\mathrm{i}, \mathrm{j})$ is filled in, each cell of which has the value "true" if the components $\mathrm{i}$ and $\mathrm{j}$ are initially contacting with each other, i.e. located at the distance

$$
r_{i j}<\alpha \cdot d_{c}
$$

and the value "false" in the opposite case.

Further, during the computer experiment, at each integration step for each bound pair $\mathrm{i}-\mathrm{j}$ there is checked whether it has parted or not, under the same condition (5), and in case of inequality (5) failure, the $K(i, j)$ array obtains the "false" value. Thus, there is a gradual disappearance of the initial cohesion of materials of the road pavement layers.

The general algorithm of the method of modelling defect accumulation in road pavements is represented by a block diagram in Figure 2 and is implemented as a computer program. 


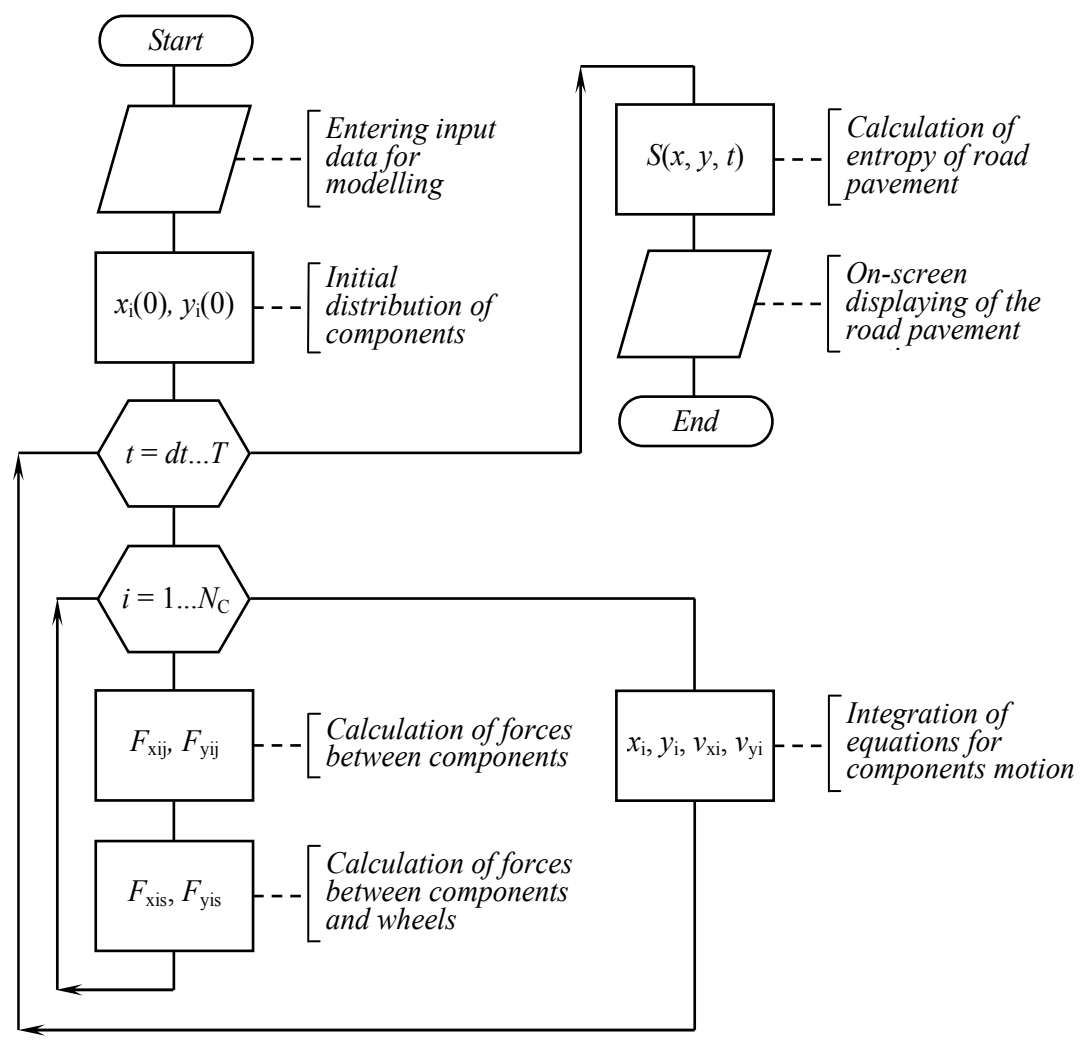

Figure 2. Diagram of the program algorithmic for modelling of defect accumulation of road pavement

The numerical integration of the equations of component motions is executed through a modified method of Euler-Cauchy. This method has the second order of accuracy in the coordinate and the first order of accuracy for speed. The method is versatile, reliable, and easily programmable. The method is implemented by the following formulas

$$
\begin{aligned}
& x_{i}=x_{i}+v_{x i} \cdot d t+\frac{F_{x i}}{m_{c}} \cdot \frac{(d t)^{2}}{2} ; \\
& y_{i}=y_{i}+v_{x i} \cdot d t+\frac{F_{y i}}{m_{c}} \cdot \frac{(d t)^{2}}{2} ; \\
& v_{x i}=v_{x i} \cdot d t+\frac{F_{x i}}{m_{c}} \cdot d t \\
& v_{y i}=v_{y i} \cdot d t+\frac{F_{y i}}{m_{c}} \cdot d t .
\end{aligned}
$$

Step of integration of the differential equation system amounted to $\Delta \mathrm{t}=0.0005 \mathrm{~s}$.

Component diameter $d_{c}$ affects the adequacy of the model. For a more accurate representation of the road pavement in the model, $d_{c}$ should be as small as possible. At the same time, the number of components $\mathrm{N}_{c}$, required for simulation, sharply increases (by a cubic law) with decreasing of $d_{c}$. At increasing the number of spheres, there is also increased the number of equations describing the layers of road pavement and, correspondingly, the time for computing. Even the twice reduction of the component diameter leads to increase of the computer calculation duration by at least eight times. If you focus on the computational power of modern computers, the optimum diameter of the component is about $5 \mathrm{~cm}$. This size provides sufficient specification of processes occurring in the road pavement, and does not lead to time-consuming calculations. The total number of components in the model may be several tens or even hundreds, depending on the type of problem being solved. 
Mass calculation of one component of a road pavement layer $\mathrm{m}_{\mathrm{c}}$ is executed using the tabulated value of material density and geometric considerations:

$$
m_{c}=\rho \cdot V_{c}=\rho \cdot \frac{4 \cdot \pi}{3} \cdot\left(\frac{d_{c}}{2}\right)^{3} \cdot k_{f}=\frac{\pi}{6} \cdot \rho \cdot d_{c}^{3} \cdot k_{f}, \mathrm{~kg},
$$

Where $\rho$ - volume density of the material, $\mathrm{kg} / \mathrm{m}^{3}$;

$\mathrm{V}_{\mathrm{c}}$ - component volume, $\mathrm{m}^{3}$;

$\mathrm{K}_{\mathrm{f}}$ - form factor necessary to account for the fact that the sphere components do not completely fill the space (unfilled pores remain between the components); $\mathrm{k}_{\mathrm{f}}$ coefficient value depends on random packing density and is equal to approximately 1.4 .

To calculate the stiffness of interaction between the two components there is used a table value of the material elasticity modulus and also the geometrical considerations concerning discretization:

$$
c_{n}=E \cdot \frac{\pi \cdot d_{c}}{4} \cdot k_{f}
$$

Where E - modulus of material elasticity, Pascal.

\subsection{Simulation within the Model of the Road Pavement Stressing from the Wheel Load}

In the developed model, simulated a multiple (up to 2000000 times) passage of an automobile along the road pavement cross-section under investigation. Each passage consists in double (for two-axle automobiles) or multiple (for multi-axle automobiles) passage of wheelset over the cross-section of the road pavement (Figure 3).

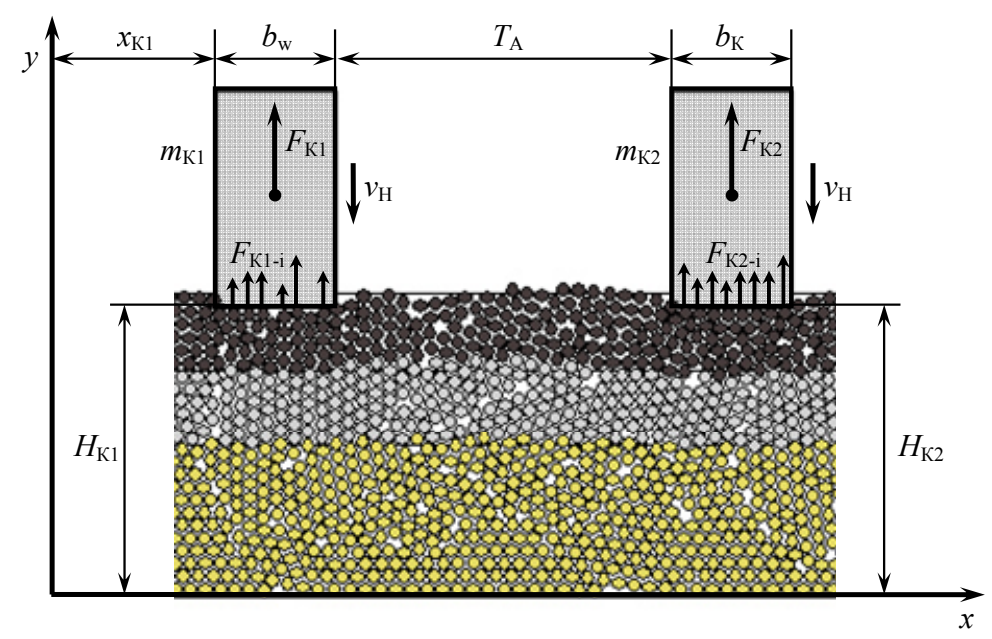

Figure 3. Design model for determination of interaction forces between wheels and road pavement components

Before the start of the simulation, there are given specific parameters for wheelsets of automobiles: wheel width $\mathrm{b}_{\mathrm{w}}$ and track $\mathrm{T}_{\mathrm{A}}$. Automobile position in the transverse direction of the road is set by the variable $\mathrm{x}_{\mathrm{K} 1}$. The model provides the possibility of automobile movement, both strictly along the track $\left(\mathrm{x}_{\mathrm{K} 1}=\right.$ const), and the possibility of accidental displacement of the track, i.e. $\mathrm{X}_{\mathrm{K} 1}$ is considered as a random variable distributed according to a normal or uniform law.

Wheel passage is modelled as follows. Initially wheel is located at a certain distance from the road surface at height $\mathrm{H}_{\text {ref }}$ (in the global coordinate system $\mathrm{XY}$ ), $\mathrm{m}$. At a certain point of time $\mathrm{t}_{\mathrm{Hn}}$ (where $\mathrm{n}-$ number of the wheelset passage), $\mathrm{s}$, within the model there starts wheel's movement down at a constant wheel $\mathrm{speed} \mathrm{v}_{\mathrm{L}}, \mathrm{m} / \mathrm{s}$. Loading velocity $\mathrm{v}_{\mathrm{L}}$ depends on the automobile speed $\mathrm{v}_{\mathrm{A}}, \mathrm{m} / \mathrm{s}$, and is associated with it, in the first approximation, through the ratio

$$
v_{L}=\frac{v_{a} \cdot k_{H}}{R_{w}}, \mathrm{~m} / \mathrm{s}
$$


Where $\mathrm{k}_{\mathrm{H}}$ - multifactor coefficient, depending on the type and profile of the wheel, material properties, type of tread, and air pressure in a wheel, $\mathrm{m}$;

$\mathrm{R}_{\mathrm{w}}$ - wheel radius, $\mathrm{m}$.

As the downward motion of the wheel, it comes into contact with the surface of the components, wherein there is a plurality of forces between the components and the wheel $\mathrm{F}_{\mathrm{K} 1-\mathrm{i}}\left(\right.$ or $\mathrm{F}_{\mathrm{K} 2 \mathrm{-i}}$ ), which together make up surface reaction force $\mathrm{F}_{\mathrm{K} 1}\left(\right.$ or $\mathrm{F}_{\mathrm{K} 2}$ ). Checking contact of the $\mathrm{i}$-th component of road pavement with a wheel is carried out by the condition of entering the centre of the component $\left(\mathrm{x}_{\mathrm{i}}, \mathrm{y}_{\mathrm{i}}\right)$ into the geometric area corresponding to the wheel, and defined by a system of inequalities:

$$
\begin{gathered}
\text { For left wheel }\left\{\begin{array}{l}
x_{i}>x_{\kappa 1} ; \\
x_{i}<x_{\kappa 1}+b_{w} \cdot T_{w} ; \\
y_{i}>H_{\kappa 1}-d_{c} / 2,
\end{array}\right. \\
\text { For right wheel }\left\{\begin{array}{l}
x_{i}>x_{\kappa 1}+b_{w} \cdot T_{w}+T_{A} ; \\
x_{i}<x_{\kappa 1}+2 \cdot b_{w} \cdot T_{w}+T_{A} ; \\
y_{i}>H_{\kappa 2}-d_{c} / 2,
\end{array}\right.
\end{gathered}
$$

where $\mathrm{H}_{\mathrm{k} 1}$ and $\mathrm{H}_{\mathrm{k} 2}$ - current position of the lower points of the wheels, $\mathrm{m}$.

Meanwhile, forces $\mathrm{F}_{\mathrm{kk}-\mathrm{i}}$ (where $\mathrm{k}$ - wheel index acquiring values 1 or 2), resulting in contact between the wheel and the components of road pavement, calculated in viscoelastic approximation as follows

$$
F_{\kappa k-i}=c_{\kappa c} \cdot\left(x_{i}-H_{k k}+d_{c} / 2\right)+d_{\kappa c} \cdot\left(v_{y i}-v_{H}\right), \mathrm{N},
$$

Where $\mathrm{c}_{\mathrm{kc}}-$ coefficient of stiffness, $\mathrm{N} / \mathrm{m}$;

$\mathrm{d}_{\mathrm{KC}}-$ viscous friction (damping) coefficient, $\mathrm{N} \cdot \mathrm{s} / \mathrm{m}$ when interacting with the wheel surface material.

These coefficients are determined by the elastic moduli of materials of wheel and the top layer of the road pavement. The total reaction force on the wheel $F_{k k}$ is determined by summing the individual forces $F_{k k-i}$ :

$$
\begin{aligned}
& F_{v k}=\sum_{i=1}^{N_{C}}\left\{\begin{array}{l}
c_{k c}\left(x_{i}-H_{k k}+d_{c} / 2\right)+d_{k c}\left(v_{y i}-v_{H}\right), \text { if }\left\{\begin{array}{l}
x_{i}>x_{k 1}+\left\{\begin{array}{l}
0, \text { if } k=1 ; \\
b_{w} \cdot T_{w}+T_{A}, \text { if } k=2 ;
\end{array}\right. \\
x_{i}<x_{k 1}+\left\{\begin{array}{l}
b_{w} \cdot T_{w}, \text { if } k=1 ; \\
2 \cdot b_{w} \cdot T_{w}+T_{A}, \text { if } k=2 ;
\end{array}\right. \\
y_{i}>H_{k k}-d c / 2 .
\end{array}\right.
\end{array}\right. \\
& F_{k k}=\sum_{i=1}^{N_{C}}\left\{\begin{array}{l}
x_{i}<x_{k 1}+\left\{\begin{array}{l}
0, \text { if } k=1 ; \\
b_{w} \cdot T_{w}+T_{A}, \text { if } k=2 ;
\end{array}\right. \\
0, \text { if }\left[\begin{array}{l}
x_{i}>x_{k 1}+\left\{\begin{array}{l}
b_{w} \cdot T_{w}, \text { if } k=1 ; \\
2 \cdot b_{w} \cdot T_{w}+T_{A}, \text { if } k=2 ;
\end{array}\right. \\
y_{i}<H_{k k}-d_{c} / 2 .
\end{array}\right.
\end{array}\right.
\end{aligned}
$$

Contact forces between the wheel and components $\mathrm{F}_{\mathrm{kk}-\mathrm{i}}$ affect both on the wheel and the components themselves, causing their displacements that extend across the entire road pavement. The force $\mathrm{F}_{\mathrm{kk}-\mathrm{i}}$ is added to the horizontal by the $\mathrm{Y}$-axis component $\mathrm{F}_{\mathrm{yi}}$ of all forces affecting on the $\mathrm{i}$-th component.

Each wheel causes formation of a flexural bowl, moves downward at a constant velocity to the point at which the reaction force $F_{k k}$ compensates weight $m_{k} \cdot g$ attributable to one wheel (where $m_{k}$ - automobile weight, attributable to one wheel). After that, in the model there begins an upward movement of the wheels at a constant velocity, for clarity substituting road pavement restoration after removal of the load, i.e. wheel's passage forward 
from the considering place of loading. This restoration is equal by modulus $\mathrm{v}_{\mathrm{H}}$, and occurs until the wheel is raised to the initial height $\mathrm{H}_{\mathrm{ref}}$ - elastic recovery is complete. Thus, the current velocity of the wheel $\mathrm{v}_{\mathrm{kk}}$, alternately takes the values that $-\mathrm{v}_{\mathrm{H}}$ (flexure under the wheel), the $\mathrm{V}_{\mathrm{H}}$ (exit from the flexural bowl). To determine the time, at which it is necessary to change the direction of the wheels on the opposite, at each integration step, there should be compared the current height of the wheels $\mathrm{H}_{\mathrm{k} 1}$ and $\mathrm{H}_{\mathrm{k} 2}$ with the height $\mathrm{H}_{\mathrm{ref}}$, and current forces of reaction to the wheels $\mathrm{F}_{\mathrm{K} 1}$ and $\mathrm{F}_{\mathrm{K} 2}$ with the weight of the automobile, attributable to one wheel $\mathrm{m}_{\mathrm{K}} \cdot \mathrm{g}$ :

Here, the first and second conditions are the conditions of motion direction change; the third is the condition of direction conservation.

This cyclic loading of wheels is made during the computer experiment until the number of passages of reference axes reaches a predetermined value $\mathrm{N}_{\mathrm{c}}$. The main series of computer experiments were performed at $\mathrm{N}_{\mathrm{c}}$ equal to $250000,500000,1000000,2000000$.

$$
v_{k k}=\left\{\begin{array}{l}
v_{H}, \text { if }\left\{\begin{array}{l}
v_{k}<0 ; \\
F_{k k}>m_{k} g ;
\end{array}\right. \\
-v_{n}, \text { if }\left\{\begin{array}{l}
\left\{\begin{array}{l}
v_{k}>0 ; \\
H_{k 1}>H_{r e f} \\
H_{k 2}>H_{r e f}
\end{array}\right. \\
{\left[\begin{array}{l}
v_{k k}<0 ; \\
F_{k k}<m_{k} g ;
\end{array}\right.} \\
\left\{\begin{array}{l}
v_{k}>0 ; \\
\left\{\begin{array}{l}
H_{k 1}<H_{r e f} \\
H_{k 2}<H_{r e f}
\end{array}\right.
\end{array}\right.
\end{array}\right.
\end{array}\right.
$$

\subsection{Simulation of Deformation and Destruction of Road Pavement within the Model}

Degradation of strength and smoothness of road pavement is associated with a number of processes occurring under the influence of automobile wheels: bending, compression, plastic deformation, additional tightening, decompression, destruction of connectedness. In the developed model, road pavement is provided with a high degree of detail, so all of these processes are reproduced at the level of changes in the structure components. The ability to simulate the microstructure allows for quantitative calculations of these processes.

Bending layers of road pavement, mainly the upper ones, are simulated in a model due to the wheels effect on the covering layer and simultaneously maintain connectivity between the components that are in series (Figure 4, a).

Compression of the road pavement layers is reproduced in the model through the approximation of components to each other (the distance between the components $r_{i j}$ becomes less than the equilibrium distance $d_{i}+d_{j}$ ) Figure 4, b. Compression is expressed as stronger, as closer are the components to place of wheels contact with the surface. Approximation of components to each other gives rise to repulsive forces between them, which creates a supporting force to the wheel, and after wheels passage, the components are returned in the approximate coverage to its original state.

Plastic deformation is expressed in the model by relative movement of closely contacting components relative to each other. Taking into account the theoretical and experimental work of Zhustareva, Y.V. and field observations of Lugov, S.V., we can neglect the thinning out effect possible under displacement processes (Zhustareva, 2000; Lugov, 2004). The model is reproduced as a local plastic deformation (inelastic displacement of a part of coating material) (Figure 4, c), and "globalized" plastic deformation: for road pavement layers, the impact of the wheel in one place is squeezing the material elsewhere; for example, track (Figure 4, d). 
Tightening is simulated by reduction of pore volume and other loose fragments of structure under the influence of wheel (Figure 4, d). Under the influence of strains from the wheels, loose fragments of local structure are experiencing restructuring and compacted. The initial (for example, construction), degree of packing of the particles is established through the actual coefficient of the standard tightening

$$
K_{y}=\frac{\rho}{\rho_{s t}}=\frac{S_{d g}}{S},
$$

Where $\rho$ - the density of the material or soil in the layer, $t / \mathrm{m}^{3}$;

$\rho_{\mathrm{st}}-$ density of the material or soil determined by standardized laboratory tests, $\mathrm{t} / \mathrm{m}^{3}$;

$\mathrm{S}$ - the area occupied by components of the layer model (particles) per unit of volume, $\mathrm{m}^{2}$;

$\mathrm{S}_{\mathrm{dg}}$ - area corresponding to the greatest degree of convergence of the layer model components per unit of volume, $\mathrm{m}^{2}$.

A number of components is taken as a volume width.

Destruction of the road pavement reproduced cohesion is simulated in the model by removing from consideration of bonds initially present in the model (Figure 4, e). Prior to the beginning of computing experiment in the cohesive layers of the model there is performed storing of contacting components, and in the further calculations it is considered that the ultimate tensile strength between the initially cohesive components is higher than between others. Under the influence of the same wheel, at a considerable distance of cohesive components from each other, there is executed setting to zero of information concerning the cohesiveness in a separate array, cohesion is eliminated, and a pair of components, even if they will again be in contact with each other, interact only through repulsive forces. 


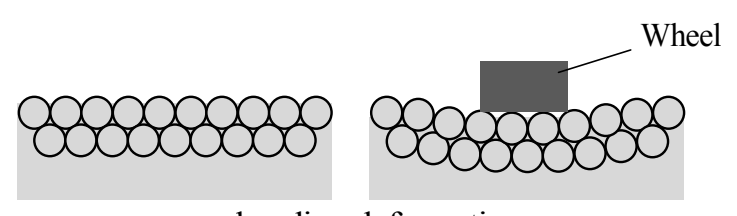

$a$-bending deformation

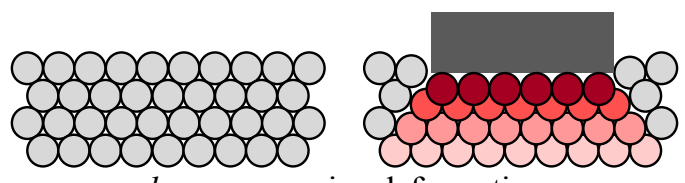

$b$-compressive deformation

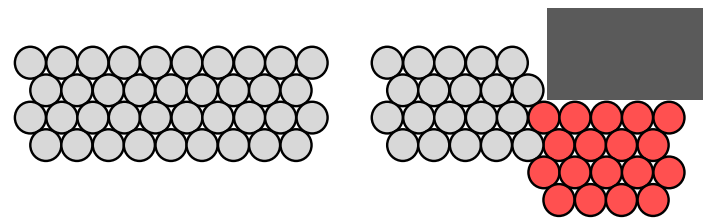

$c$ - local plastic deformation

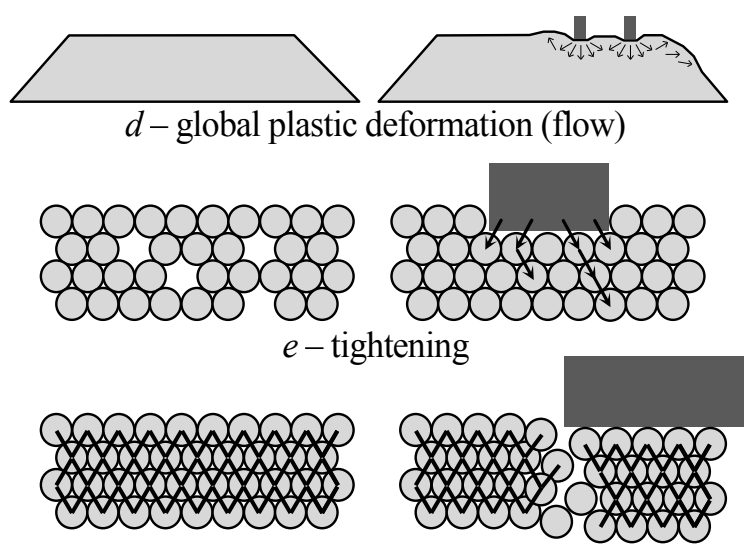

$f$-destruction (disappearance of strong bonds)

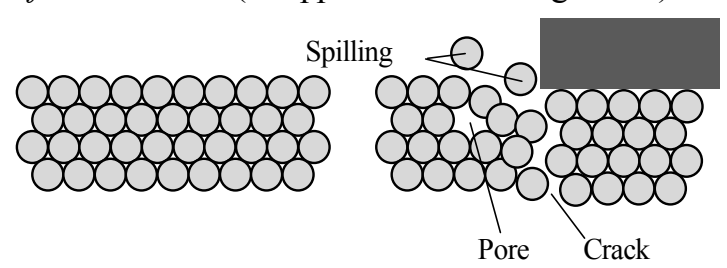

$g$ - occurrence of cracks, pores, spillage

Figure 4. Simulation in the model of basic processes that occur in road pavement under loading

Cracks, pores and spillage are reproduced in a model by removing components from each other under the action of stresses propagating from the wheel (Figure 4, g). Removal of structural fragments from each other in a model causes cracks, pores, some components which are not associated with others.

These processes in the road pavement may occur simultaneously or may not be pronounced. The advantage of the developed model is the ability of quantitative checking of all mechanical and material characteristics of these processes. Furthermore, the model appears to reproduce more complex processes involving a large number of components that are difficult to be monitored and classified. Discretization of road pavement and the use of the method of particle dynamics make the model natural for this problem, so we can expect that the model is highly appropriate. Fidelity processes should increase with decreasing size of the components in the model.

Thus, the developed model simulates a wide range of processes in the road pavement that occur during the operational period. This model allows us to make calculations of basic parameters characterizing the deformation and fracture of road pavements: energy parameters (work of deformation and destruction (entropy), dissipated heat energy), the displacement of components of layers, formation of surface irregularities, including track.

In the development of physically fundamentally new models, check on adequacy can be made by comparing the 
results obtained with analogues of others, but already proven approaches. Thus, to determine the residual strain in the "road pavement-subgrade" system, one can use the upgraded dependence of Mevlidinov, Z.A. (Mevlidinov, 1997) or complex solutions of Lugov, S.V. (Lugov, 2004) that meet the following essential requirements:

1. Comply with modern ideas about the processes occurring in the "road pavement-subgrade" system, to be constructed on theoretical assumptions, backed by numerous experimental studies, including different scientific areas and schools, and contain only the common parameters and characteristics that have received theoretical and experimental support.

2. Allow, at an integrated calculating base, to produce calculations of plastic defects in a defragmented manner by layers, i.e. possess, perhaps, if not absolute then sufficiently wide unification.

3. Allow to operate with a set of input parameters, including correction factors for determinations, which do not need mandatory live-update values and stability properties, laboratory testing of road construction materials and soil, i.e. possess permanent actualization and operational practicality. This rule does not apply to the minimum required information on the road pavement structure, intensity and composition of traffic.

4. Permissible error, not exceeding values and not leading to the rejection of the result, which distorts the assessment of the forecast of the road pavement state, expressed in terms of performance criteria. It is clear that the latter requirement is inherent in some convention. With the technical and economic point of view, such an error is convenient to estimate the costs of inputs, such as quantities of materials.

Outside of Russia, such models were developed by F. Finn, I. Gachwendt, S. Hushek, A. Molenaar, P. Ullidtz, B. Larsen Watanatada (Finn, 1982; Gachwendt \& Poliacek, 1987; The World Bank, 1997; Hushek, 1977; Molenaar, 1983; Watanatada, Hrall, Paterson, Dhareshwar, Bhandari \& Tsunokava, 1987; Ullidtz, 1987; Ullidtz \& Larsen, 1986; Grzybowska \&. Salamon, 1991).

\section{Results}

\subsection{Mechanisms of Defects Development and Nature of Changes of Operational Integrity Indicators}

Computational experiments have shown that the nature of defects in the road pavement will be different depending on the physical and mechanical properties of the materials in operating conditions, loading parameters. Accordingly, with the various changes in dynamics, the efficiency parameters are also changed within the operation of road pavement.

Stage evaluation of computer experiments revealed three possible causes that lead to the loss of flatness: additional tightening, to be more precise, a displacement and a combined mechanism.

Process of additional tightening of road pavement are realized in the case of high values of the elastic modulus and internal friction coefficient of road pavement layers, low temperature and moisture content, low wheel load. Entropy under these conditions is growing according to the patterns close to exponential (Figure 5, a). In the operation of the road structure there are shown two stages: I - initial stage of quick enough additional tightening, at the same time the change in structure leads to an increase in entropy; II - stabilizing step, in which virtually no further additional tightening occurs (or entropy is increased).

The mechanism of flow-displacement is realized in the case of low values of the elastic modulus and internal friction coefficient of road pavement layers, high temperature and humidity, large wheel load (Figure 5, b). The entropy at such mechanism of operational integrity loss is developed in three steps: I - the initial stage of the flow (road pavement some time saves its configuration); II - the stage of intensive course (reconfiguration according to the nature of loading); III - step of slow flow (configuration adapted to the nature of the movement, so further it changes slightly).

In the combined mechanism of operational integrity loss, characteristic of the most real cases is implemented as a tightening and displacement forms (Figure 5, c). The first step is characterised by tightening of road pavement; the second stage shows lasting of a slow start; the third stage is a rapid steady flow; during the fourth stage it practically stops.

For the processes of additional tightening, the growth pattern of entropy with a fairly high accuracy is described by an exponential law of the form

$$
S_{y d}\left(N_{C}\right)=S_{\max } \cdot e^{-\frac{N_{c}}{N_{p}}},
$$

Where $S_{\max }$ - maximum entropy, which is acquired by road pavement;

$N_{p}$ - coefficient of speed of entropy growth (the number of passages in which the value of $S_{\max }-S_{y д}$ differs from 
$\mathrm{S}_{\max }$ by e times).

For mechanism of flow, dependence of $\mathrm{S}_{\mathrm{yz}}\left(\mathrm{N}_{\mathrm{c}}\right)$ is a transition from one level to another level. Such dependence is generally analytically described by a sigmoidal function of Boltzmann (often used to describe non-equilibrium processes in physics, chemistry, economics, and biology)

$$
S_{y d}\left(N_{C}\right)=S_{2}+\frac{S_{1}-S_{2}}{1+e^{\frac{N_{c}-N_{c 0}}{N_{p}}}}
$$

Where $S_{1}$ and $S_{2}$ - initial and final levels of entropy;

$\mathrm{N}_{\mathrm{c} 0}$ - typical number of passages, at which the tendency of growth $\mathrm{S}_{\mathrm{yд}}$ is changed (inflection point of the sigmoid function).
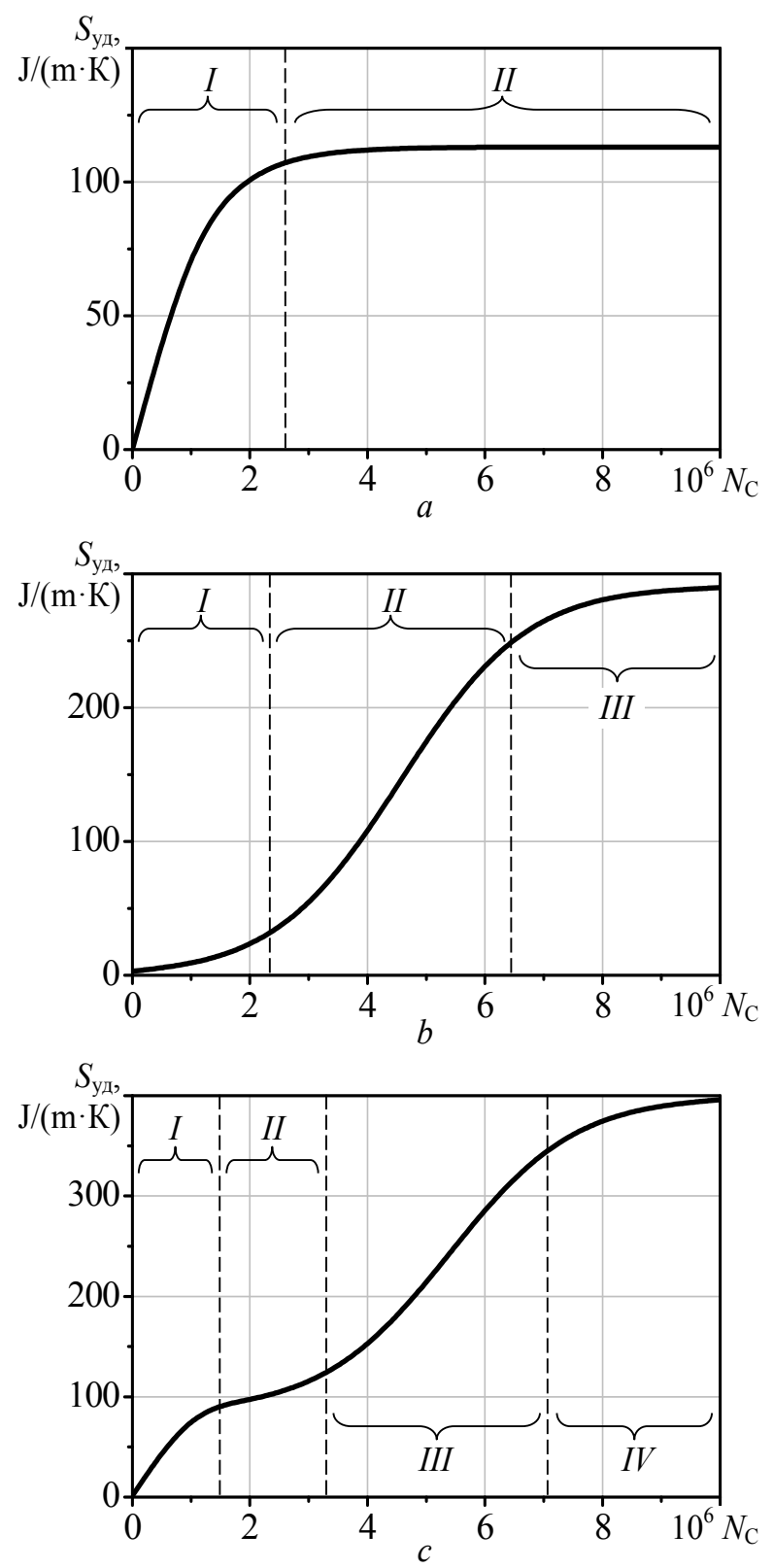

Figure 5. Nature of $\mathrm{S}_{\mathrm{yд}}$ entropy growth of the road pavement with increasing amounts of automobile passages for three mechanisms of operational integrity loss

$\mathrm{a}$ - additional tightening; $\mathrm{b}$ - flow-displacement; $\mathrm{c}$ - combined mechanism 
For the combined mechanism, first occurs additional tightening within the layers of road pavement by the formula (16), then flow by the formula (17). Therefore, in general the analytical expression can be written as the sum of two terms, each of which is responsible for its own specific loss of operational integrity. Moreover, the initial level of entropy can be adopted to zero $S_{1}=0$.

$$
S_{y d}\left(N_{c}\right)=S_{\max } \cdot e^{-\frac{N_{c}}{N_{p 1}}}+S_{2} \cdot\left(1-\frac{1}{1+e^{\frac{N_{c}-N_{c 0}}{N_{p 2}}}}\right),
$$

Where $\mathrm{N}_{\mathrm{p} 1}$ and $\mathrm{N}_{\mathrm{p} 2}$ - coefficients of entropy speed growth, respectively, for the tightening regime and the regime of plastic deformation.

\subsection{Software Implementation of the Model}

To solve the above mentioned differential equations and study of the model, there has been developed a series of computer programs distinguishing themselves by detail and speed calculations, united in the "Program for modelling of road pavement distraction" in Object Pascal in an integrated programming environment Borland Delphi 7.0. Received is a certificate of official registration of the computer program No.: 2010123456.

The program is designed to study the influence of the main mechanical and geometrical characteristics of the road pavement and subgrade characteristics of traffic flow on the road on the growth of dynamics and nature of entropy of defect accumulation in the road pavement.

The basic functionality of the program:

- Conducting computer simulations of the multiple stressing of road pavement through wheel load;

- Specifying the basic parameters of materials of the road pavement layers, subgrade and traffic load;

- Displaying in the computer experiment of schematic cross-sectional images of the road, displacement maps covering components, basic output characteristics.

When you run the program, on the screen appear interface forms with lots of entry windows, in which you can specify the geometrical and mechanical parameters of the existing road pavement and the wheels of automobiles.

\section{Conclusion}

The developed physical and mathematical apparatus and the simulation model allow studying the relations and conversion of heat in layered systems and a special form of energy - entropy with the further determination of the degree of irreversible deformation and damage of road pavements. Operational integrity of road pavement is as higher, as smaller is the value of entropy characteristics. Representation of physical fundamentally of the new model can be tested for adequacy by comparing the results obtained with analogues of others, but already proven approaches.

\section{References}

Andrei, R. (2000). The Use of Entropy Concept in Ranking and Correlating Roughness Measurements Obtained by Different Equipment. Second International Workshop on Artificial Intelligence and Mathematical Techniques in Pavement and Geomechanical Systems, Newark, DE, 153-164.

Chakrabarti, C., \& Boltzmann-Gibbs, D. (2000). Entropy: Axiomatic Characterization and Application. International Journal of Mathematics and Mathematical Sciences, 23(4), 243-251.

Chakrabarti, C., \& Chakrabarty, I. (2005). Entropy: Axiomatic Characterization and Application. International Journal of Mathematics and Mathematical Sciences, 17, 2847-2854.

Finn, F. (1982). The use of distress prediction subsystems for design of pavement Structures. Proceedings of 5 Int. Conference on the Structural Design of Asphalt Pavement, Delft.

Gachwendt, I., \& Poliacek, I. (1987). Navrochovanie a posudzovanie konstrukcji vozovek cestnych komunikacji. Bratislawa.

Gaskell, D. (2003). Introduction to the Thermodynamics of Materials (4th ed.). New York: Taylor \& Francis Books, Inc.

Goryachev, M. (2014a). Energy states of nonrigid road pavements at simulation modeling by motor transport impact. Antiseismic construction. Safety of constructions, 1, 60-62. 
Goryachev, M. (2014b, June). Energy criteria for assessment of nonrigid road pavement efficiency. MADI Herald, 2(37), 99-101.

Grzybowska, W., \&. Salamon, J. (1991). Metody przewidywania glembokosce kolei ze szczegolnym uwzglednieniem metody Husheka. Drogownictwo, 4-5, 80-85.

Hushek, S. (1977). Evaluation of rutting due to viscous flow in asphalt pavements. Proceedings of 4 Int. Conference on the Structural Design of Asphalt Pavements, Ann Arbor, Michigan.

Lugov, S. (2004). Main provisions of the methodology for calculating track depth on the road pavements with asphalt covering. Dissertation, candidate of engineering sciences, Moscow.

Martyushev, L., \& Seleznev, V. (2006). Maximality principle of entropy production in physics and related fields. Ekaterinburg: GOU VPO UGTU-UPI.

Mevlidinov, Z. (1997). Justification of the main indicators, which take into account the effect of residual strains when calculating road pavements of nonrigid type. Dissertation, candidate of engineering sciences, Moscow.

Molenaar, A. (1983). Structural performance and design of flexible road construction and asphalt concrete overlays. Delft University of Technology, Laboratory for Road and Railroad Research.

Sandler, S. (1989). Chemical and Engineering Thermodynamics (2nd ed.). Canada, Toronto: John Wiley \& Sons, Inc.

Smirnov, A. (1989). Theoretical and experimental studies of the nonrigid road pavement efficiency. Dissertation, doctor of engineering sciences, Omsk.

Smirnov, A., \& Aleksandrov, A. (2009). Mechanics of road constructions. Study Guide. Omsk: SibADI.

The World Bank (1997). Highway Development and Management, HDM-4. Washington DC: The World Bank.

Ullidtz, P. (1987). Pavement analysis. Else Vies Science Published B.V.

Ullidtz, P., \& Larsen, B. (1986). Mathematical model for predicting pavement performance. Transportation Research Record, 4, 48-55.

Watanatada, T., Hrall, C., Paterson, W., Dhareshwar, A., Bhandari, A., \& Tsunokava, K. (1987). The Highway Design and Maintenance Standard Model, 2 volumes. Baltimore, Maryland.

Zhustareva, Y. (2000). Influence of cohesive soil density in the subgrade working layer on residual strains of nonrigid road pavements. Dissertation, candidate of engineering sciences, Moscow.

\section{Copyrights}

Copyright for this article is retained by the author(s), with first publication rights granted to the journal.

This is an open-access article distributed under the terms and conditions of the Creative Commons Attribution license (http://creativecommons.org/licenses/by/3.0/). 